\title{
The Impact of Social Media on Self- Perception Among College Students
}

\author{
Ariana Galante ${ }^{1 *}$ and Nafees Alam² \\ ${ }^{1}$ College of Staten Island, USA \\ ${ }^{2}$ Researcher, Yeshiva University, USA
}

Submission: July 24, 2019; Published: August 09, 2019

"Corresponding author: Ariana Galante, College of Staten Island, USA

\begin{abstract}
Background: Many today view the world through the lens of social media. Identity management on social media platforms elicit numerous disadvantages regarding individuals and how they perceive themselves relative to the outside world. It can be difficult to oppose the idea that social media triggers the detriment of mental well-being, potentially altering the perception of self. This study aims to bridge the existing gap in literature between social media and self-perception among college students.
\end{abstract}

Methods: This quantitative study employed an 11-item questionnaire. The study was broken down into three crucial components. The first component produced affect-related statements about social media with underlying implications regarding self-esteem, thought processes, emotions and social comparison. The second component proposed exposure to social media for 10 consecutive minutes, and the third component had subjects rate their agreement once more with the same affect-related statements.

Results: The 11 pre-test and post-test affect-related statements indicated negative ideals about self-perception of each subject that participated, thus signifying a negative correlation. After statistical hypothesis testing, it has been determined that the results of the data set are statistically significant suggesting an inverse relationship between the independent variable and dependent variable.

Conclusion: The researchers observed that social networking sites challenge traditional perceptions of self, self-presentation tactics and social behavior. Social media inhibits strong peer presence and it is vital to understand how this dynamic plays a role in society today. It is critical to study social media in the context of self-perception due to the sparsity of research studies conducted.

Keywords: Social Media; Social Networking; Perception; Individuals; Body-Image; Social Comparisons; Mental Well-Being

\section{Introduction}

Social media is embedded in our social climate as we know it today, having a critical influence on our mindset. Social media has produced deep-seated changes in the dynamic by which people interact with one another. These changes have altered conventional aspects of individual behavior and self-perception. When considering the growth of social media, it is imperative to acknowledge how it influences the way individuals perceive themselves and aim to be perceived. The purpose of this research study is to understand the effects of social media and how it influences self-perception, thought processes, emotions and selfesteem. It is important to be aware of the impact of social media on self-perception. Social media users expose many aspects of their lives, browse their feeds consistently to stay updated, relevant and informed. This study aims to offer insight into how individuals browse and process the information on their social media feeds in addition to how this information manifests and impacts selfperception.

\section{Background}

Social media platforms are prevalent among teens and young adults. There is skepticism around social networking sites and how they impact individual mental health and self-perception. When examining the literature related to social networking sites, the keywords "social media," "body image," "perception" and "mental health" were used to search across national libraries. The literature explores the impact of social networking sites and the way they impact individual perceptions of themselves and the world around them. Meta-analysis articles reference individual research studies within the article to finalize their conclusions [1-3]. Each reviewed article provides similar sample sizes and subjects. The articles reviewed were published within the last ten years, when social media came to be more popular. Articles related to specific social networking sites and the associated adverse effects are sparse. 
Most reviewed articles show data collections through similar outlets. Three out of the 10 reviewed articles were meta-analyses, referencing individual studies within the articles in which they collected the data and finalized their findings regarding social media and how it alters perception. Regarding inclusion and exclusion, the 3 journal articles that are meta-analyses collected their data from subjects that exhibit preferable traits that matched the findings that they were looking for such as body image concerns and social comparisons [1-3]. "How Many Likes Did I Get?", "Internet Use Associated Body-Surveillance Among Female Adolescents," "Strategic Image Management Online" and "The Impact of Social Media on Social Comparison and Envy in Teenagers" utilize the 10-item Rosenburg Self-Esteem Likert scale to collect data [4-7]. Most of the reviewed studies recruited subjects that are female students, also many of the studies have a higher percentage of Caucasian subjects. Only one study reviewed exclusively Thai subjects [5]. Sample sizes for all reviewed studies do not go below 100, generally ranging from 102 to 250 .

Body image is a trend found throughout much of the reviewed literature, extensively discussing the effects on females. Few reviewed articles explicitly discussed body image concerns $[2,7,8]$. Perloff [2] sheds light on the topic of mental health by reviewing studies to credit the notion that there is a correlation between exposure to body-ideals on social media platforms and distortion in the perception of body image. Vukovic [7] and colleagues also discuss body image concerns for adolescents related to social media, finding that higher frequency of exposure to, and usage of, social media correlates with adolescents' beliefs on ideas physical appearance as well as attractiveness being associated with appearance comparison and weight dissatisfaction. It is also stated that the interactive aspect of social media plays a significant role in these effects.

Furthermore, Clay [8] and colleagues observed that viewing ultra-thin or averaged-sized models led to a decrease in both body-image perception and self-esteem in adolescent females, resulting in changes in self-esteem stemming from changes in body satisfaction. In comparison, Burrow [4] and colleagues, Perloff [2], and Yang [9] and colleagues discussed the correlation between individuals primarily harboring vulnerability characteristics and validation seeking related to the feedback loop and higher selfesteem that is triggered by "likes." Prevalent among the reviewed articles is how positive feedback or "likes" is also linked to higher self-esteem. For example, female adolescents' beauty ideals are largely derived from observation of their peers' Instagram pictures and feedback to those pictures. Receiving a higher number of "likes" was positively correlated with self-esteem for those who had a lower sense of purpose in life.

\section{Identity and Mental Well Being in Literature}

Charoensukmongkol [5] and Brendenburg [10] concluded that there is a positive correlation between depression and intense social media exposure. Results from Baruth [1] also noted that adolescents with lower self-esteem who did not perceive their friendships to possess good quality or value on social media are more prone to the risk of depressive symptoms. Intense exposure to social media also appeared to correlate a with anxiety and friend contingent self-esteem positively.

High exposure along with personal attachments to social media also showed susceptibility to envy and social comparisons in adolescents. Social comparisons of ability of social media are prevalent in low identity clarity. Social media also serves as a platform for adolescents to present themselves as popular, wellrounded and attractive, one of the primary goals of youth's social media self-presentation. Another trend the articles convey is the defining feature of social comparison, which is competition, as most social media users strive to fulfill this need by putting forth a positive image of themselves leading to performing more of such comparisons to develop a brief image that impresses others. Competitive drives and comparisons efficiently produce a positive correlation concerning depression, envy, and shame $[1,5,9,10]$.

\section{Gaps and Limitations in Literature}

Within the literatures reviewed, one major limitation is the lack of ethnic diversity regarding the subjects recruited. It is difficult to extract the external validity when the highest percentage of subjects recruited are Caucasians, save for one journal article by Charoensukmongkol [5]. Additionally, gender is to be considered when recruiting subjects and it is important to note that females are recruited more than males. However, although females are proven more susceptible to the adverse effects of social media, specifically body image, it is hard not to question the effects it has on males and would be beneficial to understand the external validity of these effects [11].

Regarding females, another limitation is that many articles exaggerated body image concerns, and it is important to consider facial features and the effects of photoshop and photo manipulation beyond the simple factor of body-image concerns alone. Moving forward, Facebook is the leading social media site when reviewing the studies conducted. Although the value of Facebook holds weight, Instagram and Twitter appear to be the most used and popular platforms among adolescents today; older adults also appear to use Facebook more excessively than adolescents and young adults. With that said, another gap is the lack of older adults when thinking of subject recruitment and it would be useful to measure these effects regarding the adult population as well. Furthermore, consideration of the gaps and limitations of the information gathered will benefit future research studies of how social media impacts self-perception.

\section{Methodology}

\section{Overall design}

Subjects of this study had taken the questionnaire during the Spring 2019 semester. The overall design of this study was quantitative and helped the researchers understand behaviors regarding social media and self-perception. The quantitative 
methods employed within this study involved a 11-item questionnaire. The study was broken down into three crucial components.

a) Affect-related statements about social media with underlying implications regarding self-esteem, thought processes, emotions and social comparison.

b) Exposure to social media for 10 consecutive minutes

c) Subjects rated their agreement once more with the same affect-related statements.

This research study is important because the primary goal was to explore self-perception and the extent to which self-esteem, thought processes, and social media alter emotions. There are theoretical reasons to believe that social media has an impact, yet this study exhibited credibility. Through this approach, the subjects were able to inhibit a better understanding of their behaviors and thought processes concerning social media. Additionally, the approach allowed the researchers to widen the scope about social media and the impact of self-perception. It is through the approach that the researchers gained better acknowledgment regarding social media and the effects on a quantitative scale.

\section{Subjects and sampling}

Subjects who had participated in the questionnaire consisted of 51 mentally healthy college students. The questionnaire had taken place in a quiet, classroom setting. The questionnaire was distrubted in person and physical form. There were no specific preferred demographics needed for the study because it helped generalize the findings. However, age and gender were noted yet ignored to allow generality. The age of the subjects varied. Purposive-convenience sampling was used because it was more opportune means in selecting subjects for the study. As part of the research study, subjects used social media frequently. However, the subject sample were recruited from the College of Staten Island's Master of Social Work program and undergraduate students because young adults appear to navigate social media frequently. All subjects expressed agreement of participation.

\section{Data collection}

The first part of the study consisted of 11 statements about social media, and subjects rated their agreement from 1-5 with one being "Strongly Disagree" to 5 being "Strongly Agree" on a Likert Scale. Subjects then browsed Instagram, Snapchat, and Facebook for 10 consecutive minutes. Once the subjects were finished browsing, they once again reviewed the 11 statements and rated their agreement from 1 (Strongly Agree) to 5 (Strongly Disagree) on a Likert Scale. The statements were minimum to lessen the participant's burden. These 11 items were adapted to measure the psychological effects of social media and to scale the intensity of these effects. The questionnaire consisted of the following statements:

a) There are unattainable standards of beauty I feel pressured to reach. b) I cannot help but compare myself to my peers.

c) The number of likes on a photo is a source of validation.

d) Instagram/Facebook/Snapchat is a part of my daily routine.

e) Being on Instagram/Facebook/Snapchat offers me a sense of belonging.

f) Photoshop helps me deal with the anxiety from the judgment of others.

g) The number of likes on a photo is a source of self-esteem.

h) I often compare my physical attributes to others.

i) I feel anxiety after posting a photo or status update.

j) Other people's success is an indication of my own failures.

k) Other people's lives are more fulfilling than mine.

The researchers then collected data through the interview process and observing the behaviors of participants while the study was conducted. Before completing any data collection, approval from the College of Staten Island Institutional Review Board was received.

\section{Data analysis}

This quantitative study observed the data gathered from the survey's distributed to the subjects. Data from the quantitative study was extracted from a data collection in the form of a questionnaire. The data analysis allowed an outlook on the external validity of the data collected. The purpose of the study was to derive assertions about the larger population and from which the sample is selected as well as observing a relationship in the data collected. The quantitative design gathered data from the subjects before and after browsing social media for 10 consecutive minutes with the same affect-related questionnaire. Once the data was reviewed, the quantitative analysis required the conversion of the data collected from the questionnaire into numerical codes using SPSS. Bivariate correlation was used to analyse pre-test and post test results from the 11 affect-related statements before and after the intervention of browsing social-media for 10 consecutive minutes.

\section{Ethics and human subject considerations}

This study was approved by the IRB. Subjects understood that the purpose of the study was to measure the impact of social media on self-perception regarding self-esteem, thought processes, and emotions. The subjects were willing to participate when asked to sign an informed consent. The researchers ensured that all the subjects were adequately informed about the goal of the research, provided in writing was information about what their participation in the study entailed, what happened with the information they shared, and what their rights were regarding the study. Moreover, the subjects were provided with further detailed 


\section{Annals of Social Sciences \& Management studies}

information when they completed the study. The subjects were notified of the length of the study which was approximately less than 30 minutes to complete from start to finish. Subjects were also alerted of the setting in which the study was taking place. The informed consent advised of the potential benefits which were the contribution to benefiting the social climate and the field of social work. However, it was noted that they did not directly benefit from participation in the research study.

Regarding confidentiality, it was in the best of efforts to maintain confidentiality and any information gathered as well

\section{Findings \& Analysis}

\section{Bivariate correlation}

Table 1: Negative correlation, $r=.838, p<.05$.

\begin{tabular}{|c|c|c|c|}
\hline \multicolumn{4}{|c|}{ Correlations } \\
\hline & & Standard Beauty 1 & Standard Beauty2 \\
\hline & Pearson Correlation & 1 & $.838^{* *}$ \\
\hline \multirow[t]{2}{*}{ Standard Beauty 1} & Sig. (2-tailed) & & 0 \\
\hline & $\mathrm{N}$ & 51 & 51 \\
\hline \multirow{3}{*}{ Standard Beauty 2} & Pearson Correlation & $.838^{* *}$ & 1 \\
\hline & Sig. (2-tailed) & 0 & \\
\hline & $\mathrm{N}$ & 51 & 51 \\
\hline
\end{tabular}

Table 2: Negative correlation, $r=.734, p<.05$.

\begin{tabular}{|c|c|c|c|}
\hline \multicolumn{4}{|c|}{ Correlations } \\
\hline & & Compare Peers 1 & Compare Peers 2 \\
\hline \multirow{3}{*}{ Compare Peers 1} & Pearson Correlation & 1 & $.734^{* *}$ \\
\hline & Sig. (2-tailed) & & 0 \\
\hline & $\mathrm{N}$ & 51 & 51 \\
\hline \multirow{3}{*}{ Compare Peers 2} & Pearson Correlation & $.734^{* *}$ & 1 \\
\hline & Sig. (2-tailed) & 0 & \\
\hline & $\mathrm{N}$ & 51 & 51 \\
\hline
\end{tabular}

Table 3: Negative correlation, $r=.786, p<.05$.

\begin{tabular}{|c|c|c|c|}
\hline \multicolumn{4}{|c|}{ Correlations } \\
\hline & & Likes Validation 1 & Likes Validation 2 \\
\hline \multirow{3}{*}{ Likes Validation 1} & Pearson Correlation & 1 & $.786^{* *}$ \\
\hline & Sig. (2-tailed) & & 0 \\
\hline & $\mathrm{N}$ & 51 & 51 \\
\hline \multirow{3}{*}{ Likes Validation 2} & Pearson Correlation & $.786^{* *}$ & 1 \\
\hline & Sig. (2-tailed) & 0 & \\
\hline & $\mathrm{N}$ & 51 & 51 \\
\hline
\end{tabular}

Upon observing the data, each pre-test and post-test affectrelated statements were analyzed using individual bivariate correlation charts inSPSS. The pearson $r$-correlation was conducted as collected during the research study that can identify a subject. Confidentiality was protected by not asking participants to state or write their identity as well as not associating it with any of the concluded findings. The questionnaires were randomized before and after the study to safeguard identity, and only the researchers had access to the data collected. The subject's participation of this study was entirely voluntary, and if they decided not to participate, there was no penalty. Participation in the study did not affect the subject's grades and academic standing with CUNY, or any other colleges. Participants also were able to withdraw consent at any time. 


\section{Annals of Social Sciences \& Management studies}

beauty I feel pressured to reach," had a significant strong, negative correlation, $\mathrm{r}=.838, \mathrm{p}<.05$ (Table 1). The second affect-related statement, "I cannot help but compare myself to my peers," was a significant negative correlation, $r=.786, \mathrm{p}<.05$ (Table 2). The third affect-related statement, "The number of likes on a photo is a source of validation," had a significant strong, negative correlation, $\mathrm{r}=.739, \mathrm{p}<.05$ (Table 3). The fourth affect-related statement was, "Instagram/Facebook/Snapchat is a part of my daily routine," had a significant strong, negative correlation, $\mathrm{r}=.739, \mathrm{p}<.05$ (Table 4). The fifth affect-related statement was, "Being on Instagram/ Facebook/Snapchat offers me a sense of belonging," had a significant strong, negative correlation, $r=.738, p<.05$ (Table 5). The sixth affect-related statement was, "Photoshop helps me deal with the anxiety from the judgment of others," had a significant strong, negative correlation, $\mathrm{r}=.858, \mathrm{p}<.05$ (Table 6). The seventh affect-related statement was, "The number of likes on a photo is a source of self-esteem," $r=.677, \mathrm{p}<.05$. The eight affect-related statement was, "I often compare my physical attributes to others," $\mathrm{r}=.790, \mathrm{p}<.05$ (Table 7). The ninth affect-related statement was, "I feel anxiety after posting a photo or status update," $r=.707, p<.05$ (Table 8). The tenth affect-related statement was, "Other people's success is an indication of my own failures," $\mathrm{r}=.829, \mathrm{p}<.05$ (Table 9). The eleventh affect-related statement was, "Other people's lives are more fulfilling than mine," $r=.781, \mathrm{p}<.05$ (Table 10). The null hypothesis was rejected while the directional hypothesis was supported, as social media increases, self-perception decreases. Each affect-related statement related to negative ideals about the self-perception of each subject that participated, thus signifying a negative correlation. After statistical hypothesis testing, it has been determined that the results of the data set are statistically significant suggesting an inverse relationship between the independent variable and dependent variable.

Table 4: Negative correlation, $r=.739, p<.05$.

\begin{tabular}{|c|c|c|c|}
\hline \multicolumn{2}{|c|}{ Correlations } \\
\hline \multirow{3}{*}{ Social Media Daily 1 } & Pearson Correlation & Social Media Daily 1 & Social Media Daily 2 \\
\cline { 2 - 4 } & Sig. (2-tailed) & 1 & $.739^{* *}$ \\
\cline { 2 - 4 } & $\mathrm{N}$ & 51 & 0 \\
\hline \multirow{3}{*}{ Social Media Daily 2 } & Pearson Correlation & $.739^{* *}$ & 1 \\
\cline { 2 - 4 } & Sig. (2-tailed) & 0 & 51 \\
\cline { 2 - 4 } & N & 51 & 51 \\
\hline
\end{tabular}

Table 5: Negative correlation, $r=.738, p<.05$.

\begin{tabular}{|c|c|c|c|}
\hline \multicolumn{4}{|c|}{ Correlations } \\
\hline & & Social Media Belonging 1 & Social Media Belonging 2 \\
\hline \multirow{3}{*}{$\begin{array}{l}\text { Social Media Belong- } \\
\text { ing } 1\end{array}$} & Pearson Correlation & 1 & $.738^{* *}$ \\
\hline & Sig. (2-tailed) & & 0 \\
\hline & $\mathrm{N}$ & 51 & 51 \\
\hline \multirow{3}{*}{$\begin{array}{l}\text { Social Media Belong- } \\
\text { ing } 2\end{array}$} & Pearson Correlation & $.738^{* *}$ & 1 \\
\hline & Sig. (2-tailed) & 0 & \\
\hline & $\mathrm{N}$ & 51 & 51 \\
\hline
\end{tabular}

Table 6: Negative correlation, $r=.858, p<.05$.

\begin{tabular}{|l|c|c|c|}
\hline \multicolumn{2}{|c|}{} & Social Media Belonging 1 & Social Media Belonging 2 \\
\hline \multirow{3}{*}{ Social Media Belonging 1} & Sig. (2-tailed) & 1 & $.738^{* *}$ \\
\cline { 2 - 5 } & $\mathrm{N}$ & 51 & 0 \\
\hline \multirow{3}{*}{ Social Media Belonging 2} & Sig. (2-tailed) & $.738^{* *}$ & 1 \\
\cline { 2 - 5 } & Pearson Correlation & 0 & 51 \\
\cline { 2 - 5 } & $\mathrm{N}$ & 51 & 51 \\
\hline
\end{tabular}




\section{Annals of Social Sciences \& Management studies}

Table 7: Physical attributes to others," $r=.707, p<.05$.

\begin{tabular}{|c|c|c|c|}
\hline \multicolumn{4}{|c|}{ Correlations } \\
\hline & & Anxiety Update1 & Anxiety Update2 \\
\hline \multirow{3}{*}{ Anxiety update 1} & Pearson Correlation & 1 & $.707^{* *}$ \\
\hline & Sig. (2-tailed) & & 0 \\
\hline & $\mathrm{N}$ & 51 & 50 \\
\hline \multirow{3}{*}{ Anxiety update 2} & Pearson Correlation & $.707^{* *}$ & 1 \\
\hline & Sig. (2-tailed) & 0 & \\
\hline & $\mathrm{N}$ & 50 & 50 \\
\hline
\end{tabular}

Table 8: Anxiety after posting a photo or status update," $r=.829, p<.05$.

\begin{tabular}{|c|c|c|c|}
\hline \multicolumn{4}{|c|}{ Correlations } \\
\hline & & Sucfail 1 & Sucfail 2 \\
\hline \multirow{3}{*}{ Sucfail 1} & Pearson Correlation & 1 & $.829^{* *}$ \\
\hline & Sig. (2-tailed) & & 0 \\
\hline & & 51 & 49 \\
\hline \multirow{3}{*}{ Sucfail 2} & Pearson Correlation & $.829^{* *}$ & 1 \\
\hline & Sig. (2-tailed) & 0 & \\
\hline & $\mathrm{N}$ & 49 & 49 \\
\hline
\end{tabular}

Table 9: Other people's success is an indication of my own failures," $r=.781, p<.05$.

\begin{tabular}{|c|c|c|c|}
\hline \multicolumn{4}{|c|}{ Correlations } \\
\hline & & Lives Fulfilling 1 & Lives Fulfilling 2 \\
\hline \multirow{3}{*}{ Lives Fulfilling 1} & Pearson Correlation & 1 & $.781^{* *}$ \\
\hline & Sig. (2-tailed) & & 0 \\
\hline & $\mathrm{N}$ & 50 & 47 \\
\hline \multirow{3}{*}{ Lives Fulfilling 2} & Pearson Correlation & $.781^{* *}$ & 1 \\
\hline & Sig. (2-tailed) & 0 & \\
\hline & $\mathrm{N}$ & 47 & 48 \\
\hline
\end{tabular}

Table 10: Other people's lives are more fulfilling than mine," $r=.790, p<.05$.

\begin{tabular}{|c|c|c|c|}
\hline \multicolumn{4}{|c|}{ Correlations } \\
\hline & & Compare Physical 1 & Compare Physical 2 \\
\hline \multirow{3}{*}{ Compare Physical 1} & Pearson Correlation & 1 & $.790^{* *}$ \\
\hline & Sig. (2-tailed) & & 0 \\
\hline & $\mathrm{N}$ & 51 & 51 \\
\hline \multirow{3}{*}{ Compare Physical 2} & Pearson Correlation & $.790^{* *}$ & 1 \\
\hline & Sig. (2-tailed) & 0 & \\
\hline & $\mathrm{N}$ & 51 & 51 \\
\hline
\end{tabular}

\section{Discussion and Conclusion}

\section{Future research, gaps $\&$ limitations}

The 11 pre-test and post-test affect-related statements represented negative ideals towards self-perception. Bivariate correlation was utilized to analyze the independent variable of social media in order to determine if there is an impact among the dependent variable of self-perception. It is crucial to note that the statistical significance of these findings is agreeing to negative statements on a 5-point Likert scale, with 5 being strongly agree, thus a negative correlation and/or inverse relationship among 
the variables. The researcher wanted to discover how much of an impact there is in self-perception before and after browsing social media for 10 consecutive minutes. The reliability and validity suggest the statistical significance is strong. Previous research has supported these results and focused on similar findings.

There are different methodologies that can be implemented for future studies which can offer a deeper understanding about the social media paradigm relating to perception of self. Additionally, how individuals perceive others. A larger sample size could yield greater results, offer more detail on how subjects perceive themselves and the extent they will go to achieve fabricated perfectionism on social media platforms. In addition to this, the potential to find a differentiation among different genders and age could contribute to the validity of findings and the impact on mental health. There were a handful of limitations of the current study. There were 51 subjects whom participated, with consideration of the subtle sample size it may cause inability to generalize the results. Furthermore, age and gender were ignored when analyzing the data set and future studies can place emphasis on these factors. Within practice on both a micro and macro level, social media can pose threats to an individual's mental health and the dynamic of our social world if perceived improperly. It is ostensive that these findings suggest social media creates a new approach to socialization and self-confidence. Future research can help implement new interventions to challenging mental health issues derived from a digital standpoint.

\section{References}

1. Baruth Katey (2018) Psychological Aspects of Social Media and Mental Well-Being. Journal of Human Services. USA.
2. Perloff R (2014) Social Media Effects on Young Women's Body Image Concerns: Theoretical Perspectives and an Agenda for Research. Sex Roles 71(11-12): 363-377.

3. Prieler Michael, Choi Jounghwa (2014) Broadening the Scope of Social Media Effect Research on Body Image Concerns. Sex Roles 71(11-12): 378-388.

4. Burrow A, Rainone N (2017) How many likes did I get? Purpose moderate's links between positive social media feedback and selfesteem. Journal of Experimental Social Psychology 69: 232-236.

5. Charoensukmongkol P (2017) The Impact of Social Media on Social Comparison and Envy in Teenagers: The Moderating Role of the Parent Comparing Children and In-group Competition among Friends. Journal of Child and Family Studies 27(1): 69-79.

6. Jian Raymond Rui, Stefanone Michael (2013) Strategic Image Management Online. Information, Communication \& Society 16(8): 1286-1305.

7. Brajdić Vuković M, Lucić M, Štulhofer A (2017) Internet Use Associated Body-Surveillance Among Female Adolescents: Assessing the Role of Peer Networks. Sexuality \& Culture 22(2): 521-540.

8. Daniel Clay, Vivian L Vignoles, Helga Dittmar (2005) Body Image and Self-Esteem Among Adolescent Girls: Testing the Influence of Sociocultural Factors. Journal of Research on Adolescence 15(4): 451477.

9. Yang C, Holden SM, Carter MD (2018) Social Media Social Comparison of Ability (but not Opinion) Predicts Lower Identity Clarity: Identity Processing Style as a Mediator. Journal of Youth and Adolescence 47(10): 2114-2128.

10. Brendenburg Marja (2015) The Relationship between Social Media Use and Personality. pp. 517-528.

11. Rubin A, Babbie ER (2016) Essential research methods for social work. Boston, MA: Cengage Learning. USA.

\begin{tabular}{l} 
Your next submission with Juniper Publishers \\
will reach you the below assets \\
- Quality Editorial service \\
- Swift Peer Review \\
- Reprints availability \\
- E-prints Service \\
- Manuscript Podcast for convenient understanding \\
- Global attainment for your research \\
- Manuscript accessibility in different formats \\
( Pdf, E-pub, Full Text, Audio) \\
- Unceasing customer service \\
Track the below URL for one-step submission \\
https://juniperpublishers.com/online-submission.php \\
\hline
\end{tabular}

